\title{
From Carbon Markets to Carbon Morality: Creative Compounds as Framing Devices in Online Discourses on Climate Change Mitigation
}

Nelya Koteyko, Mike Thelwall and Brigitte Nerlich

\begin{abstract}
Lexical combinations of at least two roots around 'carbon' as the lexical hub, such as 'carbon finance' or 'carbon footprint', have recently become ubiquitous in discourses on climate change in English speaking science, politics, and mass media. They are part of a new language evolving around the issue of climate change that can reveal how it is framed as a public issue by various stakeholders, how public attitudes and perceptions are shaped and which solutions to climate change and global warming are being proposed, contested and debated. In this article, we study the role of some of these 'carbon compounds' as tools of communication in different online discourses dealing with issues of climate change mitigation. By combining a quantitative diachronic analysis of their occurrences with a qualitative analysis of the contexts in which the compounds were used, we identify three clusters of compounds focused on finance, lifestyle, and attitudes, and then elucidate the different communicative purposes to which they were put between the 1990s and the early 21 st century, reflecting a temporal shift in the debate. This approach may open up new ways of analyzing the different framings of climate change mitigation initiatives in the public sphere.
\end{abstract}

Keywords: climate change communication, frame analysis, metaphor analysis, cybermetrics, compounds

Authors' note: The authors gratefully acknowledge funding from the Economic and Social Research Council, grant number: RES-062-23-1256. Address for correspondence is Nelya Koteyko, ISS, West Wing, Law and Soc. Sciences, University Park, NG7 2RD; nelya.koteyko@nottingham.ac.uk 


\section{From Carbon Markets to Carbon Morality: Creative Compounds as Framing Devices in Online Discourses on Climate Change Mitigation}

\section{Introduction}

The issues of global warming and climate change have been in and out of the news for many years (McComas \& Shanahan, 1995). Since about 2005 they have, yet again, attracted immense print and online media coverage and generated volumes of online text in group discussions, blogs and on social networking sites. Compared to previous debates, a novel form of linguistic framing has emerged over the last decade, namely the use of what we call 'carbon compounds' ${ }^{1}$ - lexical combinations of at least two roots around 'carbon' as the lexical hub, such as 'carbon finance', 'carbon sinner', or 'low-carbon diet'. They are part of a whole new language that is evolving around the issue of climate change which needs to be monitored and investigated in order to discover how climate change is framed as a public issue by various stakeholders (Alexander, 2008), how public attitudes and perceptions are shaped and which solutions to climate change and global warming are being proposed, contested and debated. Communicating climate change is a complex activity in which many different stakeholders engage for a variety purposes and in order to achieve various results (Nerlich \& Koteyko, 2009). Apart from advice on how to reduce one's carbon footprint on individual, regional, national and global levels, advice is also proliferating on how to communicate climate change (e.g., Moser \& Dilling, 2007; Ockwell et al., 2009).

In this article, we test a novel approach based on a combination of methods derived from cybermetrics and critical metaphor analysis that allows social scientists and science communicators to listen to the voices of people active in the climate change debate and to map their activities across time and across discourses. The aim is to chart the emergence and use of 'carbon compounds' as a new lexical tool employed in climate change communication over time, as well as to explore how and why these new creations gained popularity within various groups.

\footnotetext{
${ }^{1}$ The term 'carbon compound' has of course a different meaning in chemistry.
} 
In contrast with the majority of social scientists studying climate change debates around the globe, we do not focus on traditional print media to study climate change discourses and climate change communication, but instead use a combination of blogs and news sources to investigate the dynamics of an emergent 'carbon lexicon' on the web. We first identify the most 'active' and 'creative' compounds around the word 'carbon' as the hub, follow their development over time, and then map their uses on various Internet sites. The aim is to examine the role of what we call 'creative carbon compounds' as tools of communication by combining quantitative diachronic analysis of the expanding network around the compounds with qualitative analysis of the contexts of their use.

\section{Theoretical Background}

This article is a novel contribution to various strands of interdisciplinary research concerned with the dynamics of public debates in general and climate change discourse in particular. These include, amongst others, the analysis of issue cultures, issue networks and media hypes (Ungar, 2007; Roger \& Marres, 2000; Vasterman et al., 2005); the analysis of frames (Schön \& Rein, 1994; Tankard, 2001; Scheufele \& Tewksbury 2007- among many others) and the study of metaphors as tools of communication (Hellsten, 2003; Larson et al., 2005) in the media and public policy discourse.

All of these interdisciplinary studies emphasize the crucial role played by traditional and new forms of media in public debates. As a forum where various social groups and institutions struggle over the definition and construction of issues of public concern, especially science-related matters (Nelkin, 1987), the various forms of media play a major role in issue politics (Marres, 2005) by raising awareness and amplifying ${ }^{2}$ attention. Anthony Downs (1998) was the first to study the different stages of public attention in his 'issue attention cycle'. The attention generated by an issue in the mass media is often characterised by the development of 'issue cultures' - defined by Ungar (2007: 81) as

\footnotetext{
${ }^{2}$ In this regard, media studies scholars have explored media hypes as waves of news, generated by 'self-reinforcing processes in news production' (Vasterman et al., 2005, p. 111).
} 
'cognate sets of social problems that become a commanding concern in society'. Examples include the issue cultures built around fear of emerging diseases such as SARS, avian flu (Hellsten \& Nerlich, in press), and ozone depletion (Ungar, 2007).

One of the underlying social mechanisms driving issue attention cycles is issue definition achieved through framing. A media frame is described as 'the central organizing idea for news content that supplies a context and suggests what the issue is through the use of selection, emphasis, exclusion and elaboration' (Tankard, 2001: 100-101). As framing creates the boundaries around an issue and allows certain actors to claim ownership of it, it has become one of the central categories in the study of discourse coalitions ${ }^{3}$ (a group of discourse actors bound by the shared use of language, Hajer, 1995) and in new media studies of 'issue networks' (actors linked via hyperlinks and key phrases, Roger \& Marres, 2000). With regards to climate change, numerous studies have analysed how environmental issues are framed in various discourses (Alexander, 2008; Weingart et al., 2000) and especially in national newspapers (Boykoff, 2008, Olaussen, in press; Carvalho \& Burgess, 2005) whereas far less attention has been paid to new types of media (but see Nisbet \& Kotch, 2009).

A frame can be evoked through symbols, storylines and metaphors that become indicative of it during the course of its life in discourse (Nisbet, 2009). A classic example is the study by Schön and Rein (1994) who demonstrated how 'generative metaphors' used in social policy situations (when politicians characterize the state of older project housing as 'urban blight' or 'urban decay') act as framing devices, as they make some aspects of an issue more salient while backgrounding other elements (p. 144). More recently, the important role of metaphors as framing devices has been studied, for example, in the context of public policy research focused on genetically modified (GM) food and the control of infectious diseases (Hellsten, 2003; Larson et al., 2005). The communicative potential of metaphors has also been explored with regards to the communication of environmental

\footnotetext{
${ }^{3}$ The relationship between discourse coalitions and frames has been the subject of extensive academic discussion which we will not cover here (but see Schön and Rein, 1994).
} 
issues by Valiverronen and Hellsten (2002) and Ungar (2007), who stresses the importance of 'bridging metaphors' derived from the popular culture.

As these researchers have repeatedly pointed out, metaphors can not only frame issues but can also create common ground between different discourses (Maasen \& Weingart, 1995). In this sense, 'carbon compounds' may manifest a 'double resonance' (Weingart \& Maasen, 1997) arising from the interplay of scientific and popular metaphoric meanings (Proctor \& Larson, 2005). They could therefore be useful tools for the mapping of discursive affinities between science and lay understandings of climate change (Corbett \& Durfee, 2004) on the web. Although no systematic studies seem to have been undertaken to track the metaphors used in climate change debates so far, Roger and Marres (2000) pursued a similar approach by mapping the online use of a statement from the Intergovernmental Panel on Climate Change (IPCC) as well as organizations' inter hyperlinking to create climate change 'discourse maps'.

In line with previous research, focusing on the role of communicative devices for making sense of issues, this article studies frames used in web-based discourses on the management of climate change and global warming, which we believe can be 'indexed' by carbon compounds. As compounds provide more opportunities for variation and change on the combinatorial and semantic level, compared to single words or single metaphors, we propose using them to track the dynamics of the climate change debate (see the next section). As media frames tend to vary over time in the coverage of public policy issues (Downs, 1998; Trumbo, 1996), here we focus on providing a chronological overview of the use of carbon compounds and on examining their functions in the online discourses on climate change mitigation.

Our approach shifts the focus away from measuring the success of competing frames and assessing the suitability of certain frames for climate change communication - methods which are common to previous analyses of frames in climate change media coverage. Instead, we use the framework of metaphor analysis (Lakoff \& Johnson, 1980; Zinken et al., 2008) to explore how the combination of terms, in our case carbon compounds, used not only by a variety of stakeholders but also by the general public (via online fora), may imply 
different descriptions of the current state of the issue culture. The variety of voices that can be found on the web is of particular importance, as the use of compounds on blogging sites could potentially reveal the existence of alternative climate change frames yet to be observed in the mainstream media with its close ties to policy making (Carvahlo \& Burgess, 2005). Studying the emergence and spread of carbon compounds would therefore provide new insights into patterns of collective linguistic creativity and collective epistemic processes. This might be important to policy makers looking for 'pattern recognition tools' that provide insights into the evolution, variation and change of public debates and controversies.

\section{'Creative' Compounds}

As mentioned above, much of the social scientific research on public controversies has focused on the invention and spread of metaphors and other framing devices in media, policy and practitioner discourses; whereas the repeated use of compounds representing the more collective processes of framing has been overlooked. Compounding is the most productive word formation process in English, and any number of words can be combined to form a compound. In climate change discourse this is illustrated by the creation of such multiple compounds as 'carbon mitigation cost curves' and 'carbon indulgence pixie dust' (Nerlich and Koteyko, 2009). As compounds arise from the combination or blending of two or more different lexical and ontological domains (e.g., Lieber \& Stekauer, 2009), compounding represents an important contextualization device, allowing lexical items to be grouped into clusters that share certain aspects of meaning.

Following Benczes (2006), we pay special attention to so-called 'creative ${ }^{4}$ compounds', that is, types of nominal construction that combine lexical compounding with metaphorical conceptualization. According to this definition, 'carbon emission' would be a compound but not a metaphorical one, whereas 'carbon diet' is a compound and a metaphor.

\footnotetext{
${ }^{4}$ Linguists have debated the nature of creativity and productivity in compounds for a long time, a topic we shall leave aside in this article (but see Munat, 2007)
} 
We therefore use tools from cognitive linguistics, a branch of linguistics that specializes in metaphor analysis, to identify and analyze these constructions in our corpus.

Metaphor, in general, is a discursive tool used to understand and experience one kind of thing in terms of another (Lakoff \& Johnson, 1980). In the metaphorical compounds with 'carbon' as head, some aspects of the, by now conventional, compound 'carbon dioxide' are used to concretize and make sense of new realities emerging from what one may call the 'management' of $\mathrm{CO}_{2}$, be it selling/buying (e.g., 'carbon trading') in the form of 'emissions' or reducing/calculating it (e.g., 'carbon footprint calculator'). These metaphorical compounds, which connect two domains, such as the reduction of $\mathrm{CO}_{2}$ emissions and financial management, are therefore different from literary descriptors. It should be stressed that in most carbon compounds 'dioxide' is elided and has to be inferred and 'carbon' can also stand for something other than carbon atoms alone. Take for example the compound 'carbon rationing'. In a first step one could paraphrase this compound as 'carbon dioxide rationing'. However, on closer inspection, it emerges that what one is rationing is the 'emission' of 'carbon dioxide' and more concretely, rationing the consumption of energy. This means that carbon compounds pack a lot of semantic and conceptual information into one small lexical package.

Creative metaphoric compounds have the potential to invoke strong associations and are successful to the extent that they resonate with the discourse in which they appear (Zinken et al., 2008). We therefore believe that an examination of metaphoric 'carbon compounds' offers a way to study the diverse approaches and attitudes to climate change mitigation proposed in the multiple and fragmented discourses that can be found on the web. As Hulme (2008a) points out, '[j]ust as the physical climate-system responds both to slowchanging natural rhythms and also to more rapid human-induced perturbations, so will those human artefacts we use to make sense of climate change - language, metaphors, policies, beliefs - respond both rapidly and slowly to the new financial and economic mood.' Climate modellers model the physical changes and variations in the climate system. Here we make an attempt at 'modelling' perturbations and changes in the cultural face of climate change. 


\section{'Carbon Mitigation' as a New Issue in the Climate Change Debate}

The century long debate about causes of and solutions to climate change is an example of a complex or 'wicked' policy problem (Hulme, 2008b) which has been subject to many framings emphasising different aspects of the issue. With the release of the IPCC's first assessment report in 1990 , the focus of the debate shifted to solutions, as this and subsequent reports have established relevant causal links between climate change and human behavior (anthropogenic climate change) with a high level of certainty. It is within this discursive niche that most of our carbon compounds are being used.

One of the recent framings of potential solutions proposed to curbing greenhouse gas emissions in Western industrial societies is reflected in the discourse of market environmentalism that gained ground with the Brundtland report Our Common Future and the establishment of the framework convention for climate change, the United Nations Climate Change Convention (UNCCC) in 1992. The key objectives of the convention, agreed upon by diverse countries that met under the auspices of the United Nations Earth summit, was to reduce emissions from economic activity and lessen the impact of unavoidable climatic change. The commitments under the UNCCC regarding the global economy have become known as mitigation strategies. In 1997 these were made legally binding by the Kyoto protocol, which set the 'price' for carbon through mechanisms; such as Emissions Trading, the Clean Development Mechanism and Joint Implementation; to allow Annex I economies to meet their greenhouse gas (GHG) emission limitations by purchasing GHG emission reductions credits from elsewhere, through financial exchanges and other projects. This led to the development of carbon markets and, at the consumer level, the introduction of individual and corporate carbon offsets (Kollmuss \& Bowell, 2007).

A distinct feature of ecological modernization is the assumption that economic growth and environmental protection are compatible and that a liberal market order and sustainable development can go together. From this perspective, ecological capitalism and industrialization can be made more environmentally friendly. As a result, as the Wall Street Journal reported, '[t]he global-warming debate is shifting from science to economics... The biggest question going forward no longer is whether fossil-fuel emissions should be curbed. It 
is who will foot the bill for the cleanup' (Carlot, 2005). Carbon compounds seem to have emerged as part of this 'carbon economy' strategy for climate change mitigation.

\section{Identification of Compounds}

In this paper we used the RSS (Really Simple Syndication) scanning method to generate a large collection of recent online text from which currently used carbon compounds could be extracted. Based on XML code that continuously reports website updates, RSS feeds are a useful tool for collecting information from a variety of websites. There is a particular advantage of using RSS feeds to collect data from a large number of blogs, as 'the simple and compact RSS format reduces web traffic and the load on the servers hosting the blogs' (Thelwall \& Stuart, 2007).

We generated a collection of 82,049 RSS feeds from search engines and RSS databases and monitored each feed daily using the purpose-built RSS collection and processing software Mozdeh (Thelwall, Prabowo \& Fairclough, 2006). Our sample of feeds is a convenience sample, as there is no single systematic register from which to select randomly. The sample essentially consists of daily updates from a wide range of blogs, news sites and other sources throughout 2007 and so is a good source of information about what was discussed online and in the news in 2007. Whilst the sample cannot claim to be representative of the web due to its ad-hoc nature, it would be strange for a carbon compound to be extensively discussed and still be absent from all the blogs and news sites included. The collection thus represents an appropriate source from which to identify recently discussed carbon compounds.

Next, a list of compounds was produced from the 2007 RSS corpus with the help of the clustering function of AntConc, a textual analysis computing tool (Anthony, 2005). This list was studied independently by two project members to identify 'creative' metaphorical compounds. Following the standard procedure for the identification of metaphors (Pragglejaz group, 2007) 34 compounds were selected for further analysis (see Table 1) by studying 
their concordances ${ }^{5}$ and, occasionally, by analyzing the wider web context in which they were used, accessed via URLs.

\section{Analysis}

It is difficult to analyze the dynamics of web-based debates, as search engines will provide hundreds of thousands of hits for truly global topics such as climate change. The analysis is further complicated by the sheer diversity of discourses, since the issue of climate change, like many public issues, is simultaneously concerned with a variety of scientific, political, economic, administrative, ethical and health related questions (Hulme, 2008b). To mitigate these difficulties, we only monitored web pages that contained a limited selection of compounds relating to one specific issue - that of climate change mitigation. The use of only 34 compounds enabled us to perform a focused, chronological analysis tracing the commonalities among the different discourses.

Our interest in the chronology of compound use led us to compile a database of contexts where compounds had been used since the beginning of the web. This basic set of data was collected using the search function of the AltaVista Advanced Search interface between 1990 and November 2008 (the end date of this search coincides with the beginning of our study). AltaVista was selected because its advanced search facility allows results to be limited to a certain time period. This search matches the last modified date of web pages, which is sometimes the creation date of a web page and sometimes the date that it was last changed (Leydesdorff \& Curran, 2000). The dates returned therefore have to be treated with caution, and note also that many older pages will have been deleted from the web and hence will not appear in the results. As the dates from AltaVista are occasionally wrong (e.g., because of incorrect file dates on the originating web servers) we cross-checked the dates when each compound started to be used by searching the Google News archive. Although both sources may produce some inaccurate data, their combination provides more reliable

\footnotetext{
${ }^{5}$ In corpus linguistics applications, a set of concordance lines presents instances of a word or phrase in the centre, with words that come before and after it to the left and right, and provides a quick access to contexts where a selected word is used.
} 
information. The 'timeline' facility of the Google News archive was also used to monitor more recent use of compounds as the AltaVista search results are limited to 1050 per year.

The contexts of occurrence were traced by downloading the relevant sites' URLs ${ }^{6}$, titles and abstracts and running them through the AntConc software (Anthony, 2005). Using the concordancing feature, the use of each compound in context was located. Words and phrases contextualising carbon compounds were identified and loosely mapped and provided the basis for our study of the different frames which are visible in changes of words or combinations of words. In this way, it became possible, for example, to study how the use of creative compounds was organised around knowledge claims (e.g., statements by carbon offsetting supporters and sceptics).

In order to reveal the network of websites where our set of compounds was used, URLs were truncated and counted to produce a list of domains. We then conducted a further analysis of sites that occurred with the highest frequency within the AltaVista search results. This allowed us to complement our diachronic analysis of compounds with the synchronic study of their distribution on various websites.

\section{The Dynamics of Carbon Compound Usage}

\section{The Use of Carbon Compounds Online between 1990 and 2008}

The longitudinal study of compounds appearing in our AltaVista corpus and on the Google News 'timeline', revealed two patterns in the use of these compounds over time. First, the number of uses of all compounds has risen rapidly from 2000 onwards, and peaked around the end of 2007 and the beginning of 2008 (according to the Google News archive, monthly usage figures were decreasing towards the end of 2008 for some compounds, in line with a general decrease in reporting on climate change issues overall, see Ward, 2008b). Second, it became possible to trace which compounds were the oldest and which began to be used only recently. Here, a tendency to cluster according to the time period and semantic set was

\footnotetext{
${ }^{6}$ Although all URLs in our corpus are unique, this did not prevent duplication as, for example, an online news article could be syndicated or reposted on several blogs.
} 
observed. Thus, as can be seen from Table 2, compounds headed by the lexis from the sphere of finance appeared to be the 'oldest' compounds, as they started to be used between the early 1990s and 1999. Exceptions are carbon payment, carbon debit and carbon deal which started to be used in semantic terms in 2000 and 2001 (carbon spewing is also an exception). The majority of middle range (1999 to 2005) compounds can be grouped under the label of 'lifestyle', although there are exceptions in semantic terms such as carbon crazy, carbon future, carbon monster. Compounds that only began to be used from 2005 onwards are headed by the emotional and evaluative lexis ${ }^{7}$ (with the exception of the 'lifestyle' compound carbon detox). Consequently, if we follow the assumption that frames or phases manifest themselves through differences in word usage (Thelwall \& Hellsten, 2006), the lifecycle of carbon mitigation as a topic can be divided into three phases: 1 ) the period between 1990 and 1999 (Figure 1), focused on issues of market and finance before the lifestyle compounds started to appear 2) the 1999-2005 period, characterised by the use of lifestyle compounds (Figure 2) and 3) the 2005-2008 period, characterised by the appearance and use of attitudinal compounds (Figure 3).

[Figure 1 about here]

[Figure 2 about here]

[Figure 3 about here]

Below we look at each cluster in more detail and present the overall trends resulting from this necessarily limited qualitative enquiry. Extended contexts of use (such as the examples provided below) were obtained by following the respective URLs.

\section{The Use of Finance Compounds Online between 1990 and 1999}

The contexts in which compounds were used before 1999 show little diversity. The URLS predominantly come from governmental organization reports and news reports. Although

\footnotetext{
${ }^{7}$ The division into 'lifestyle' and 'attitudinal' lexis is made here for analytical purposes and is admittedly crude, as some of the lifestyle compounds can be used evaluatively in certain contexts.
} 
first coined around 1988 (see Oxford English Dictionary, online), carbon tax is first found online in August 1992 (in the early days of the world wide web) in a vision letter from the Chairman of the US Republican National Committee: 'We oppose any attempt to impose a carbon tax as proposed by liberal Democrats'. As we can see from Table 2, other finance compounds soon started to appear in online use in similar US political documents and reports:

The regions which have implemented a carbon tax evaluate a further tax raise; the regions which have implemented an Energy and carbon efficiency programme evaluate additional energy and carbon savings (1994, The Climate Fund, http://www.ciesin.org/kiosk/publications/94-0017.txt)

The Ministry also sponsored a two-day seminar on the carbon budget of Iceland, featuring scientific and technical lectures on natural and man-made sources and sinks for carbon in Iceland. (1997, Status Report for Iceland pursuant to the United Nations Framework Convention on Climate Change http://unfccc.int/cop3/fccc/natcom/natc/icenc2.pdf)

From 2003 onwards the frequency of some of these compounds increased to over 1050 occurrences per year (1050 being the AltaVista result limit). This high frequency is not surprising given that the economics of climate change (costing impacts, mitigation and adaptation initiatives) is a central issue in policy-making at the national and international level (e.g. DFID, 2006; IPCC, 2007). Most of the compounds therefore were coined to conceptualise 'carbon trading' between countries and corporations. The economic management of climate change does, however, have a second stage characterised by personal initiatives (such as carbon offsetting and calculating the size of individual carbon footprint) rather than national and corporate financial initiatives. These person-centred activities may have contributed to the emergence of another, frequently occurring cluster of compounds centred on lifestyle, which, as we can see from Table 2, started to proliferate on the web around the same time. 
The metaphorical fusion of economy and the production/reduction of $\mathrm{CO}_{2}$ through the process of compounding helps transform environmental objects into commercial 'goods and services'. From this perspective, as Lohmann (in press) observes, trade becomes both a comparative valuation and an environmentalist action:

There may be considerable potential benefit to the Australian environment and to biodiversity conservation values, through the introduction of a carbon credit or greenhouse gas emissions trading system. (1998, Queensland Conservation Council, http://www.aph.gov.au/HOUSE/committee/environ/greenhse/gasrpt/Sub22em.pdf)

The finance/accounting frame evoked by carbon compounds makes environmental crises more visible to decision-makers and in a sense more natural to them, by classifying them in a way that highlights quantifiable relationships with commodities and other economic objects (Lohmann, in press).

\section{The Use of Lifestyle Compounds Online between 1999 and 2005}

In the more recent group of compounds, the term carbon footprint is particularly prominent. It also seems to be the most popular compound among the general public - a November 2008 search using the Google search engine's 'trends' tool (www.google.com/trends) reveals that worldwide searches for the term 'carbon footprint' exceed those for other frequent terms such as 'carbon tax' and 'carbon offset' by more than four-to-one ${ }^{8}$. The use of this compound, which was coined around 1999 (see Oxford English Dictionary, online), spawned a new 'carbon-speak' centred on calculating individual and collective impacts. Some of the

http://www.google.com/trends?q=carbon+tax\%2C+carbon+footprint\%2C+carbon+offset\&ctab=0\&geo $=$ all\&date $=$ all\&sort $=0$ 
many posts on www.greendaily.com show how this compound was embedded in everyday lifestyle issues from wine drinking to using your mobile phone:

2 ways to calculate your carbon footprint

How to reduce your wine's carbon footprint

Use your iPhone to measure your carbon footprint and fuel usage

The use of carbon footprint with other compounds, such as carbon diet, carbon lifestyle, carbon living, constitutes and reflects a frame centered on the re-organization of life around climate change. Through the process of compounding, the noun 'carbon' is combined with the lexis from the semantic set of 'lifestyle' to evoke the frame according to which global warming is seen as a new structure for personal life. Components of this frame include the widely-shared cultural narrative of dieting and calorie counting based on a sub-cluster of such compounds as carbon calories, carbon counting, carbon calculator, and carbon detox.

Learn about the controversy surrounding the greenhouse effect, and calculate your family's 'carbon diet' in an online game. (2000, http://www.idahoptv.org/learn/thismonth/oct00.html)

We know that we will not be burning oil, gas and coal forever. And we know the environmental benefits of kicking our carbon addiction. (2001, http://www.jockgill.com/presentations/cheney_lobbies_for_a_discredited.htm)

Additionally, such compounds as carbon diet and carbon addiction work to create a moral frame as they highlight restraint (in terms of carbon consumption) as a primary ethic guiding (heroic) life-style choices. The study of other related compounds also shows an emergence of the moral or religious frame, according to which excesses are sins. The frame is perhaps best visible through the compound carbon guilt which is used to describe the production of carbon dioxide as something we should regret and/or justify:

Why Planting Trees for Carbon Guilt Doesn't Add Up (February 2004, http://risingtide.org.uk/pages/news/temperature_gauge/2004_02.htm) 
This religious frame may shift the emphasis from the account of climate as the production of a particular gas and the necessity to limit this production through lifestyle changes, to a moral story about the need for personal limitation (Appleton, 2007). However, lifestyle compounds also frame green living in ways which make it seem almost frivolous rather than frugal. As we will see, the third wave of carbon compounds reflects debates about these issues more actively.

The metaphorical compounds coined and used widely between 1999 and 2005 are employed to highlight and/or construct different links between climate change mitigation and changes in lifestyle and behavior. Depending on the lexical items combined with the noun carbon, the 'lifestyle carbon compounds' can express the message that 1) unrestrained human energy use has dangerous consequences for the natural world and therefore has to be limited by making certain lifestyle choices (e.g. carbon diet, carbon calculator, carbon living) 2) we need to take responsibility for this and change our behavior (carbon addiction, carbon guilt).

\section{The Use of Attitudinal Compounds from 2005 onwards}

The cluster of highly-evaluative compounds in use since 2005 points to exchanges of opinions on the controversial nature of climate change mitigation options. Judging from the majority of negatively-colored compounds, this period may indicate some kind of climate change fatigue (Ward, 2008). Other studies have noted that during that time the use of 'carbon credits' and 'carbon offsetting' as financial mechanisms to mitigate climate change became the subject of heated debate in the English-speaking media (Nerlich and Koteyko, 2009). Below we will briefly explore how metaphorical compounds have provided a discursive means to express this more reflexive attitude to climate change mitigation.

As Table 2 shows, the frequency of attitudinal compounds rose sharply at the end of 2006 and the beginning of 2007. During this period, such compounds as carbon morality and carbon critics, for example, are used to furnish arguments that climate change mitigation strategies are framed not as scientific observations about cause and effect but rather as a 
morality tale. In the newspapers, opinion columnists wrote about the danger of mistaking the ubiquity of the new carbon-speak for substantive change:

The two things we seem to do most instinctively are manipulate language and create markets, and those two instincts converge when it comes to carbon footprints. Creating a market in moral carbon - offsets that counter our energy-rich lifestyle - feels a little like Rotisserie baseball, more illusion than reality (June 2008, http://www.nytimes.com/2008/06/24/opinion/24tue4.html).

Although the general moral frame may have been created and perpetrated via the traditional newspapers (Nerlich \& Koteyko, 2009), the online discussions take it further as bloggers express their opinions on individual offsetting and other aspects of environmental economics that have been conceptualized with the help of finance carbon compounds such as carbon tax since the beginning of 1990s. The example below conveys a negative stance both towards the framing of climate change in economic terms and the presentation of climate change mitigation as a morality tale:

Alright Dr. Ron! Way to go. Yes, the global crime syndicate's operatives, like Al Gore, are selling the people on the guilt of 'Man-made' global warming. This way the elite can tax their little peps even more: a carbon tax, a breathing tax, a farting tax- then they sell you on suicide to save the planet. (June 2007, http://m.digg.com/politics/Ron_Paul_Slams_Global_Warming?offset=35)

The contexts of use of other attitudinal carbon compounds point to a variety of critical statements targeted at various aspects of carbon mitigation. For example, critics point out that environmental crises are rooted not in poor costing 'but in the very spread of market mechanisms and norms' into all spheres of society (O'Neill, 2007, p. 21) In this regard, compounds such as carbon delusion and carbon dictatorship are used to target and question the basis of market environmentalism: 'Kevni and his left believe they can have 'forever' control of markets and economic planning thanks to the AGW [Australian government] 
carbon delusion. (Reply to 'Doing nothing really is cheaper', September 2008, http://blogs.news.com.au).

The compound carbon critics is used to denote groups which identify with different aspects of such criticism - these groups can be 'environmental offsetting sceptics' who point out that offsetting schemes do not work because they resemble medieval indulgences that absolve you from sinful behavior but do not prevent sinful behavior in the first place, 'economic offsetting skeptics' who point out the rather cynical exploitation of carbon offsetting schemes for the purpose of personal enrichment rather than as a means to mitigate climate change, and even 'Al Gore skeptics' (Nerlich \& Koteyko, 2009).

When Al Gore, or anyone prominent for that matter, does something for the environment, the carbon critics cry footprint foul and run up staggering numbers about the actual damage that these so called do-gooders are doing in the name of good (July 2007, http://www.mydd.com/story/2007/7/7/13815/55042).

Prince [Charles] paints his transatlantic trip green to offset the carbon critics (January 2007, timesonline.co.uk)

Criticism of voluntary offsetting gained momentum with the publication of Al Gore's film and book An Inconvenient Truth (in 2006) which, despite record sales, has triggered accusations of hypocrisy expressed, inter alia, with the help of the compound 'carbon crusade' also widely used in blogs:

Al Gore's Carbon Crusade. The Money and Connections Behind It (August 2007, http://digg.com/general_sciences/Al_Gore_s_Carbon_Crusade)

During this time period, critics of the market environmentalism approach were describing voluntary offsets as the sale of 'carbon indulgences' in that they provide an easy way out without the need to change one's habits and behavior. 'Carbon Bigfoot' is another variation of the ubiquitous carbon footprint compound. Sometimes used simply to describe someone with 
a large carbon footprint (Are you a Carbon Bigfoot? Quiz rates your personal impact on the environment; www.freerepublic.com.), it is also used to express criticism, for example in statements where hypocrisy or hype around climate change are discussed, especially in relation to the activities of Al Gore who was accused of squandering energy in his mansion: 'Just more lies brought to you by the Liars Club, including Al Gore, Mr. Carbon Bigfoot himself' (December 2007, www.digg.com) ${ }^{9}$. The groups involved in the debate are, therefore, mostly 'offsetting skeptics' although voices of climate skeptics can also be discerned:

Come on Mother Nature! Get those temps dropping beyond debate so we can shut down this global warming hoax before it's too late. As miserable and long as this winter from hell has been, I'm thinking a few more like it may actually be a good thing in the long run, if that helps wake people up, and save us from carbon

dictatorship. (April 2008, http://www.freerepublic.com/focus/fnews/2008634/posts)

Broadly speaking, attitudinal carbon compounds are used as a tool for expressing skepticism regarding various aspects of climate change mitigation initiatives. In line with previous research focused on the comparison of frames in blogs in the media (Glass, 2005), this most recent 'wave' of carbon compounds reveals the existence of alternative frames that present viewpoints and analysis which do not occur in the mainstream media. Their discursive role is therefore different from that of finance and lifestyle compounds. Due to their strong (negative) connotations they provide an evaluative frame of reference which can supersede other conceptual frames. Whenever these evaluative/critical compounds are used, they convey the writer's stance on the overall issue, which can, at the same time, be conceptualized with the help of other compounds (e.g., financial), such as 'carbon indulgence dealer' in the following example:

\footnotetext{
${ }^{9}$ In the popular imagination, Bigfoot is a monster who wanders in the woods in the American Far West.
} 
BTW, has anyone considered the 'carbon footprint' of the San Antonio

conference? How does the AIA plan to offset such a Sasquatch-ian ${ }^{10}$ impression?

Perhaps it could come up with a carbon tax like Boulder, CO has done.

Alternatively, perhaps Mr. Gore could recommend a reputable carbon

indulgence dealer. I think the AIA should stop drinking the Kool-Aid and pay

attention.

This type of carbon compound emphasizes the dramatic dimensions of the climate change mitigation issue - especially morality and ethics - and can therefore form part of the 'symbolically urgent' tactics that are often employed to attract wider public attention and concern (Cobb \& Elder, 1983).

\section{A Synchronic Study of Websites Using the Compounds}

As one might expect, finance compounds are ubiquitous and were used across the whole range of domains (in the sense of domain name endings). The use of lifestyle compounds is equally widespread (edu, com, org, gov) and reflects the take-up of 'eco-ethics' by various scientific, political, educational, religious, business, and artistic institutions that, since about 2000 , have become involved in the promotion of awareness about climate change and called for the public to limit their energy consumption. Attitudinal compounds tend to be used more by blogging and news sites.

The first 20 most frequently used domains for all of the compounds were also scrutinized individually to find out which compounds were used and which were omitted and how frequently. The distribution of compounds on the websites revealed two tendencies. First, some of the websites contained whole clusters of semantically-related compounds rather than high frequencies of individual ones which may point to the collective role of compounds in discourse. ${ }^{11}$ Thus, a website where 'carbon tax' or 'carbon credit' was used was found likely to contain other finance compounds such as 'carbon accounting', 'carbon budget' and so on. Second, there are websites that contain only compounds from one

\footnotetext{
${ }^{10}$ In American culture, Sasquatch is the supposed name of Bigfoot.

${ }^{11}$ There are only 4 instances where a single compound is used by a single website.
} 
semantic group (e.g., finance or lifestyle compounds only, which may be indicative of the organization's position and function within climate change discourse. For example, governmental websites (publicationsparliment.uk; carbontrust co.uk) contained a range of finance and lifestyle compounds but no attitudinal ones, such as carbon morality or carbon crusade, for example, which may indicate a lack of debate on these websites. The website of the United Nations Convention for Climate Change (Unfccc.com) contains only finance compounds. Blogging sites, for example www.blogs.com.ua, use a range of evaluative compounds together with finance and 'lifestyle' carbon compounds. (As has been mentioned above, these other compounds are often embedded in the overall criticism conveyed by their more evaluative/critical neighbors). These clustering tendencies are significant in terms of the structuring role of the compounds and will be discussed below.

Table 3 in the appendix lists only some of the main websites using the compounds. In the process of selection, attention was paid not only to the frequency of compound tokens but also to the heterogeneity of compounds as used per domain, i.e. the number of compound types. As a result of such selection, the first candidates for inclusion were domains that contained semantically-diverse compounds. For example, the website ajax.sys-con.com which contains 654 instances of carbon footprint only - was not included in the list ${ }^{12}$, whereas www.climatespace.org containing carbon footprint, carbon living, carbon challenge, carbon lifestyle (and only one compound type belonging to the semantic set of finance carbon accounting) was taken as a good example of a website employing predominantly 'lifestyle' carbon compounds to structure its online messages. The UK newspaper websites display a wide range of both attitudinal and lifestyle compound types and therefore are listed in both columns.

\section{Discussion}

\footnotetext{
12 Other instances where only 1 or 2 compounds were used include www.carbonfootprint.com, tomshardware.com, www.pointcarbon.com, www.carbonfinance.org, www.greenpowerconferences.com.
} 
This study used searches in AltaVista and Google News to gain insights about the use of creative carbon compounds by various sites on the Internet over time. Metaphoric compounds may be much less spectacular than some of the metaphors that have been used to structure public debates in the past, but in the case of climate change they have emerged as a framing device well fitted to the complexity of the issue itself. In themselves trivial and easily overlooked, en masse they structure some aspects of English climate change discourse in intriguing ways (Nerlich and Koteyko, 2009).

Scholars of political communication point out that for complex issue areas, such as climate change, 'there are a plethora of possible debates and cleavages that can take place' (Drezner \& Farrell, 2004, p.17). Using carbon compounds we have, in this study, shown how both the mainstream media and blogs create 'focal points' (id., p. 22 ) in the wider public debate on climate change mitigation as they provide interpretive frames that highlight certain aspects of the issue. The combination of pages from both news sources and blogs has provided us with a broad spectrum of contemporary discussion, as we were able to study the usage of compounds in a wide range of sources that employ different communication strategies and have a variety of motivations. Although such a sample presents difficulties for social scientific research (compared to samples with a narrower set that have clear parameters as far as its creators are concerned), this type of corpus provides insights into the role of compounds as communication tools both in terms of framing (conceptual framing) and structuring (providing lexical cohesion). We now move on to discuss each of these functions in more detail.

According to the theory of metaphor (Lakoff \& Johnson, 1980), the essence of metaphor is to reflect and induce conceptual change: for example, metaphors make something difficult comprehensible, and/or they give a name to something that cannot be expressed otherwise. Consequently, one of the main uses of metaphoric compounds, as illustrated especially by finance and lifestyle compounds, is to open up a new perspective on the issue of climate change mitigation because they allow their users to talk about carbon dioxide emissions in terms of cost and credit or in terms of changes to individual lifestyles. They can naturalize carbon mitigation options for policy makers by mapping them onto 
financial options and they can naturalize them for ordinary people by mapping them onto everyday lifestyle choices, from paying taxes to choosing the right wine'. In other instances, compounds such as 'carbon guilt' and 'carbon detox' are used to create a religious/moral frame that can shift attention from environmental questions to questions of personal morality. They also tend to question and scrutinize what might otherwise come to be seen as 'the natural option', according to the frames afforded by compounds that exploit the conceptual spaces of finance and lifestyle. From this perspective, creative 'carbon compounds' serve as traditional framing devices (metaphors and other imagery) in that they allow the carving out a certain conceptual space that provides a particular angle on an issue.

In addition to this conceptual framing, compounding may be used to provide an inherent and often invisible structure to a debate. As the study of the distribution of compounds on websites revealed, compounds are rarely used alone in a single website and even in a single text. Instead, one can talk about the combined use of compounds when an issue is debated online. The use of one compound often conditions the use of another when the writer needs to substantiate or contrast his or her viewpoint. As a result, certain websites contain clusters of specific compounds (e.g. dealing with financial or lifestyle aspects of climate change mitigation). From this perspective, compounds can be seen as the building blocks of discursive maps (Roger \& Marres, 2000). The use of compound clusters can be studied to reveal the nature of the relations and positions taken by various actors online. Absence of certain compounds, as in our example, the absence of evaluative compounds such as 'carbon morality' and 'carbon crusade', can be just as revealing.

\section{Conclusions}

Based on a novel combination of quantitative and qualitative methods, this study has traced the use of creative compounds on the web and analyzed their use in the framing of the climate change mitigation issue. Carbon compounds first started to be used in online media when the web was initiated in the early 1990s, gained popularity after 2000 and reached a peak in usage in 2008 (after which at least some of the compounds were used less frequently, a trend that overlaps with a decrease in media coverage around climate change). 
Throughout this period, carbon compounds were used as an effective tool to communicate different approaches, framings and attitudes related to the complex and urgent problem of climate change.

Communicators have been grappling with the idea of how to put the issue of global warming onto the public agenda (Ockwell et al., 2009), calling for in-depth communication research to tailor messages to the existing attitudes, values, and perceptions of different audiences (Nisbet, 2009; reference after review). According to the sociologist Sheldon Ungar:

Ultimately the trick will not be done by technological fixes but in the emergence of relevant issue cultures and potent bridging metaphors that engage a wide population in the necessary behaviour and political change. It would be nice if one could suggest what these might be, but they are best regarded as emergent elements of ongoing efforts to confront the threat of climate change. (Ungar, 2007, p. 87)

Carbon compounds studied in this article are examples of an emergent shared 'carbon lexicon'. They can therefore be used to study the ways in which the issue of carbon emissions is already being framed, and they demonstrate its hold over social life and public debate. Compounds can be seen as indicators for key junctures in a debate. They convey relevant meaning concisely and economically, as they lexically and conceptually compress issues under discussion into just two or more words. Some of them are 'attention grabbing' and based on common vocabulary. These tokens of collective creativity can therefore be harvested and used in climate change communication in order to avoid the common pitfalls of science communicators, who have been accused of using words that are 'well meaning' but 'too dull' or of using too much scientific jargon. They are already part of what some commentators call for: a 'common climate language' (see Bowman et al., 2009).

For reasons of space we could only briefly comment on the discursive role of compounds within the framework of metaphor analysis but hope that our approach will inspire further, more situated study of their use. The literature on environmental discourse analysis (Hajer, 1995; Dryzek, 1997) shows that frames do not develop in a political 
vacuum, but are shaped by competing claims-makers. Further studies can look at how different discourse coalitions use carbon compounds to help define their boundaries of activity, lend coherence to their discourse, and position themselves and others. By looking at how different groups use the compounds online to describe themselves, their work and their adversaries, such studies can begin to uncover the ubiquitous and patterned systems of language and thought that underlie attitudes and behavior. They might also allow climate change communicators to see where the public debate is going and gauge possible reactions to proposed communicative interventions.

\section{References}

Alexander, R. (2008). Framing discourse on the environment: A critical discourse approach. New York, London: Routledge.

Anthony, L. (2005). AntConc: Design and development of a freeware corpus analysis toolkit for the technical writing classroom. Proceedings of Professional Communication Conference, 10-13 July, pp. 729-737.

Appleton, J. (2007, May 25). Measuring the political temperature. Spiked online. Retrieved December 10, 2008, from http://www.spikedonline.com/index.php?/site/boxarticle/3406/.

Benczes, R. (2006). Creative compounds in English. Amsterdam: John Benjamins.

Boykoff, M. T. (2008). Lost in translation? United States television news coverage of anthropogenic climate change, 1994-2004. Climatic Change, 1-11.

Bowman, T. E., Maibach, E., Mann, M. E., Moser, S. C., \& Somerville, R. C. J. (2009). Creating a common climate language. Science, 324(5923), 36b-37.

Carlot, J. (2005, April 25). J.P. Morgan adopts 'green' lending policies. Wall Street Journal, April 25, p. B1.

Carvalho, A. \& Burgess, J. (2005). Cultural circuits of climate change in U.K. Broadsheet Newspapers 1985-2003. Risk Analysis, 25(6), 1457-69.

Cobb, R. W. \& Elder, C. D. (1983). Participation in American politics: The dynamics of agenda-building. Boston: Allyn \& Bacon. 
DFID (2006). Key sheets on climate change and poverty. Department for International Development, London. Retrieved 12 January, 2009, from http://www.dfid.gov.uk/pubs/files/climatechange/keysheetsindex.asp.

Downs, A. (1998). Political theory and public choice. Northampton, MA: Edward Elgar.

Drezner, D. \& Farrell, H. (2004). The power and politics of Blogs. Paper presented at the annual meeting of the American Political Science Association, Hilton Chicago and the Palmer House Hilton, Chicago, IL . Retrieved 14 April 2009, from http://www.utsc.utoronto.ca/ farrell/blogpaperfinal.pdf.

Dryzek, J. (1997). The politics of the Earth. Oxford: Oxford University Press.

Fauconnier, G. \& Turner, M. (2002). The way we think. New York: Basic Books.

Glass, G. (2005). A Balkanized Blogosphere? Retrieved 10 April, 2009, from http://www.geof.net/research/2005/05/13/balkan-blogs/balkan-blogs.html.

Gore, A. (2006). An inconvenient truth. New York: Rodale Press.

Hajer, M. (1995). The politics of environmental discourse. Ecological Modernisation and the Policy Process. Clarendon Press: Oxford.

Harvey, F. \& Fidler S. (2007, April 25). Industry caught in carbon 'smokescreen'. Financial Times. Retrieved 29 December, 2008, from http://www.ft.com/cms/s/48e334ce-f355-11db-9845-000b5df10621.html.

Hellsten, I. (2003). Focus on metaphors: The case of 'Frankenfood' on the Web. Journal of Computer-Mediated Communication, 8, 4. Retrieved 12 December, 2008, from http://www.ascusc.org/jcmc/vol8/issue4/hellsten.html.

Hulme, M. (2008a). Amid the financial storm: Redirecting climate change. Retrieved December 12, 2008, from: http://www.opendemocracy.net/article/amid-the-financialstorm-redirecting-climate-change.

Hulme, M. (2008b). Why we disagree about climate change: Understanding controversy, inaction and opportunity. Cambridge: Cambridge University Press.

IPCC (2007). Impacts, adaptation and vulnerability, Annex B. Contribution of Working Group II to the Fourth Assessment Report of the IPCC. Cambridge: Cambridge University Press. 
Kolmuss, A., \& Bowell, B. (Eds.). (2007). Voluntary offsets for air-travel carbon emissions: Evaluations and recommendations of voluntary offset companies. Massachusetts: Tufts University. Retrieved 10 December, 2008, from http://www.tufts.edu/tie/tci/pdf/TCI_Carbon_Offsets_Paper_April-2-07.pdf

Lakoff, G., \& Johnson, M. (1980). Metaphors we live by. Chicago: Chicago University Press. Larson, B., Nerlich, B., \& Wallis, P. (2005). Metaphors and biorisks: The war on infectious diseases and invasive species. Science Communication, 26(3), 1-26.

Leydesdorff, L. \& Curran, M., (2000). Mapping university-industry-government relations on the Internet: the construction of indicators for a knowledge-based economy, Cybermetrics, 4. Retrieved from: http://www.cindoc.csic.es/cybermetrics/articles/v4i1p2.html.

Lieber, R. \& Stekauer, P. (2009). The oxford handbook of compounding. Oxford: OUP. Lohmann, L. (in press). Toward a different debate in environmental accounting: The cases of carbon and cost-benefit. Accounting, Organizations and Society.

Maasen, S. \& Weingart, P. (1995). Metaphors - messengers of meaning. A contribution to an evolutionary sociology of science. Science Communication, 17(1), 9-31.

Marres, N. (2005). No issue, no public. Democratic deficits after the displacement of politics. Amsterdam: Ipskamp Printpartners.

McComas, K. \& Shanahan, J. (1999). Telling stories about climate change. Measuring the impact of narratives on issue cycles. Communication Research, 26(1), 30-57.

Moser, S. C. \& Dilling, L. (2007). Creating a climate for change: Communicating climate change and facilitating social change. Cambridge: Cambridge University press.

Munat, J. (Ed.) (2007). Lexical creativity, texts and contexts. Amsterdam: John Benjamins Publishing Company.

Nelkin, D. (1987). Selling science. How the press covers science and technology. New York: WH Freeman.

Nisbet, M. C. (2009). Communicating climate change: Why frames matter to public engagement. Environment, 51(2), 12-23. 
Nisbet, M.C. \& Kotcher, J.E. (2009). A two-step flow of influence? Opinion-leader campaigns on climate change, Science Communication, 30(3), 328-354.

Ockwell, D., Whitmarsh, L. \& O'Neill, S. (2009). Reorienting climate change communication for effective mitigation. Science Communication, 30(3), 305-327.

Olausson, U. (in press). Global warming-global responsibility? Media frames of collective action and scientific certainty. Public Understanding of Science.

O’Neill, J. (2007). Markets, deliberation and environment. London: Routledge.

Pragglejaz (2007). MIP: A method for identifying metaphorically used words in discourse. Metaphor and Symbol, 22(1), 1-39.

Proctor, J. \& Larson, B. (2005). Ecology, complexity and metaphor. BioScience, 55(12), 1065-1068.

Rogers, R., \& Marres, N. (2000). Landscaping climate change: A mapping technique for understanding science and technology debates on the World Wide Web. Public Understanding of Science, 9(2), 141-163.

Scheufele, D., \& Tewksbury, D. (2007). Framing, agenda setting, and priming: The evolution of three media effects models. Journal of Communication, 57(1), 9-20.

Schön, D. \& Rein, M. (1994). Frame Reflection: Toward the Resolution of Intractable Policy Controversies. New York: Basic Books.

Tankard, J. (2001). The empirical approach to the study of media framing. In: Framing public life: Perspectives on media and our understanding of the social world, S. D. Reese, O. H. Gandy, and A. E. Grant (Eds.), Mahwah, NJ: Lawrence Erlbaum Associates.

Thelwall, M. \& Hellsten, I. (2006). The BBC, Daily Telegraph and Wikinews timelines of the terrorist attacks of 7th July 2006 in London: a comparison with contemporary discussions. Information Research, 12(1) paper 84. Retrieved from: http://InformationR.net/ir/12-1/paper284.html

Thelwall, M., Prabowo, R. \& Fairclough, R. (2006). Are raw RSS feeds suitable for broad issue scanning? A science concern case study. Journal of the American Society for Information Science and Technology, 57(12), 1644-1654. 
Thelwall, M. \& Stuart, D. (2007). RUOK? Blogging communication technologies during crises. Journal of Computer-Mediated Communication, 12(2), article 9. http://jcmc.indiana.edu/vol12/issue2/thelwall.html

UNFCCC (1997). Kyoto Protocol: countries included in Annex B to the Kyoto Protocol and their emissions targets. United Nations Framework Convention on Climate Change. Retrieved 10 December, 2008, from http://unfccc.int/kyoto_protocol/background/items/3145.php

Ungar, S. (2007). Public scares: Changing the issue culture. In: S. Moser \& L. Dilling, (Eds.), Creating a climate for change: Communicating climate change and facilitating social change (pp. 81-88). Cambridge: Cambridge University Press.

Väliverronen, E. \& Hellsten, I. (2002). From "Burning Library" to "Green Medicine". The role of metaphors in communicating biodiversity. Science Communication, 24, 229-245.

Vasterman, P., Yzermans, J., \& Dirkzwager, A. J. E. (2005). The role of the media and media hypes in the aftermath of disasters. Epidemiologic Reviews, 27, 107-114.

Ward, B. (2008). 2008's year-long fall-off in climate coverage: Tracking the trends, and the reasons behind them. Yale Forum on Climate Change \& the Media. Retrieved 2 January, 2009, from http://www.yaleclimatemediaforum.org.

Weingart, P. \& Maasen, S. (1997). The order of meaning: The career of chaos as a metaphor. Configurations, 5, 463-520.

Weingart, P., Engels, A. \& Pansegrau, P. (2000). Risks of communication: Discourses on climate change in science, politics, and the mass media. Public Understanding of Science, 9, 261-83.

Zinken, J., Hellsten, I. \& Nerlich, B. (2008). Discourse metaphors. In: R. Frank, R. Dirven, R., et al., (Eds.) Body, language and mind, vol. 2: Sociocultural situatedness. Amsterdam: John Benjamins, pp. 363-386.

\section{Author biographies}

Nelya Koteyko's research lies at the intersection of corpus linguistics, media studies, and metaphor analysis; she has authored or co-authored papers in these areas for Health, 
Applied Linguistics, Sociological Research Online, Critical Discourse Studies and Corpora. Current research involves linguistic creativity and discursive framing of climate change.

Mike Thelwall is Professor of Information Science and leader of the Statistical Cybermetrics Research Group at the University of Wolverhampton, UK. He has developed tools for downloading and analysing web sites, blogs and social networking sites, including the research web crawler SocSciBot and software for statistical and topological analyses of site structures (through links) and site content (through text). He has published 142 refereed journal articles and two books, mainly focusing on methods for gathering and analysing web data.

Brigitte Nerlich is Professor of Science, Language and Society at the Institute for the Study of Genetics at the University of Nottingham, UK. Her most recent research focuses on the cultural and political contexts in which metaphors are used in public and scientific debates about biotechnology, health and illness and climate change.

Table 1: List of creative carbon compounds

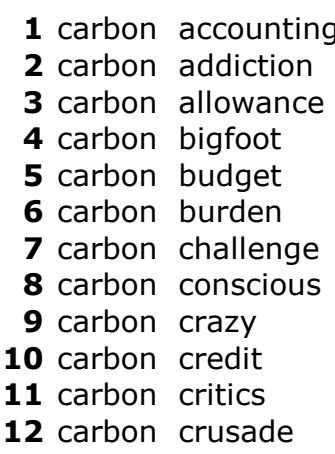

Creative carbon compounds

$\begin{array}{ll}\mathbf{1 3} \text { carbon deal } & \mathbf{2 4} \text { carbon } \\ \mathbf{1 4} \text { carbon debit } & \mathbf{2 5} \text { carbon lifestyle } \\ \mathbf{1 5} \text { carbon delusion } & \mathbf{2 6} \text { carbon living } \\ \mathbf{1 6} \text { carbon detox } & \mathbf{2 7} \text { carbon management } \\ \mathbf{1 7} \text { carbon dictatorship } & \mathbf{2 8} \text { carbon market } \\ \mathbf{1 8} \text { carbon diet } & \mathbf{2 9} \text { carbon morality } \\ \mathbf{1 9} \text { carbon footprint } & \mathbf{3 0} \text { carbon payment } \\ \mathbf{2 0} \text { carbon future } & \mathbf{3 1} \text { carbon saving } \\ \mathbf{2 1} \text { carbon friendly } & \mathbf{3 2} \text { carbon sinner } \\ \mathbf{2 2} \text { carbon guilt } & \mathbf{3 3} \text { carbon spewing } \\ \mathbf{2 3} \text { carbon hero } & \mathbf{3 4} \text { carbon tax } \\ \mathbf{2 4} \text { carbon indulgence } & \end{array}$

Table 2: frequencies of compounds per year in AltaVista (maximum: 1050). Note that older figures are likely to be underestimates compared to later figures due to old pages being deleted from the web by 
their owners.

\begin{tabular}{|c|c|c|c|c|c|c|c|c|c|c|c|c|c|c|c|c|c|}
\hline Query & 1992 & 1993 & 1994 & 1995 & 1996 & 1997 & 1998 & 1999 & 2000 & 2001 & 2002 & 2003 & 2004 & 2005 & 2006 & 2007 & 2008 \\
\hline $\operatorname{tax}$ & 3 & 1 & 2 & 6 & 15 & 35 & 85 & 174 & 287 & 310 & 466 & 722 & 952 & 1050 & 1050 & 1050 & 1050 \\
\hline budget & 2 & 4 & 6 & 6 & 22 & 74 & 113 & 202 & 391 & 440 & 617 & 1050 & 1050 & 1050 & 1050 & 1050 & 1050 \\
\hline market & 0 & 0 & 0 & 1 & 1 & 0 & 8 & 15 & 83 & 114 & 202 & 320 & 652 & 1050 & 1050 & 1050 & 1050 \\
\hline management & 0 & 0 & 0 & 3 & 4 & 10 & 13 & 44 & 106 & 155 & 412 & 459 & 860 & 1050 & 1050 & 1050 & 1050 \\
\hline saving & 0 & 0 & 0 & 1 & 1 & 0 & 5 & 12 & 15 & 12 & 33 & 63 & 89 & 234 & 434 & 1050 & 1050 \\
\hline credit & 0 & 0 & 0 & 0 & 2 & 3 & 19 & 31 & 93 & 110 & 211 & 418 & 470 & 1050 & 1050 & 1050 & 1050 \\
\hline spewing & 0 & 0 & 0 & 0 & 1 & 1 & 0 & 2 & 0 & 2 & 2 & 1 & 4 & 11 & 12 & 162 & 1050 \\
\hline allowance & 0 & 0 & 0 & 0 & 0 & 1 & 0 & 2 & 3 & 15 & 7 & 24 & 35 & 92 & 197 & 676 & 1050 \\
\hline burden & 0 & 0 & 0 & 0 & 0 & 1 & 1 & 2 & 0 & 1 & 19 & 12 & 21 & 38 & 51 & 140 & 1050 \\
\hline accounting & 0 & 0 & 0 & 0 & 0 & 0 & 20 & 27 & 123 & 137 & 178 & 310 & 445 & 675 & 1050 & 1050 & 1050 \\
\hline footprint & 0 & 0 & 0 & 0 & 0 & 0 & 0 & 5 & 6 & 35 & 33 & 71 & 170 & 1050 & 1050 & 1050 & 1050 \\
\hline friendly & 0 & 0 & 0 & 0 & 0 & 0 & 0 & 4 & 2 & 4 & 9 & 12 & 21 & 39 & 68 & 504 & 1050 \\
\hline living & 0 & 0 & 0 & 0 & 0 & 0 & 0 & 0 & 4 & 3 & 4 & 4 & 5 & 64 & 232 & 256 & 1050 \\
\hline diet & 0 & 0 & 0 & 0 & 0 & 0 & 0 & 1 & 2 & 3 & 3 & 13 & 19 & 61 & 181 & 1050 & 1050 \\
\hline future & 0 & 0 & 0 & 0 & 0 & 0 & 0 & 2 & 3 & 2 & 21 & 41 & 106 & 227 & 461 & 1050 & 1050 \\
\hline debit & 0 & 0 & 0 & 0 & 0 & 0 & 0 & 0 & & 8 & 6 & 5 & 4 & 11 & 18 & 72 & 909 \\
\hline hero & 0 & 0 & 0 & 0 & 0 & 0 & 0 & 0 & 1 & 0 & 0 & 0 & 2 & 1 & 2 & 62 & 1050 \\
\hline monster & 0 & 0 & 0 & 0 & 0 & 0 & 0 & 0 & 2 & 0 & 1 & 1 & 2 & 12 & 9 & 15 & 105 \\
\hline challenge & 0 & 0 & 0 & 0 & 0 & 0 & 0 & 0 & 1 & 9 & 13 & 25 & 31 & 41 & 130 & 727 & 1050 \\
\hline payment & 0 & 0 & 0 & 0 & 0 & 0 & 0 & 0 & 0 & 1 & 8 & 10 & 24 & 18 & 28 & 54 & 800 \\
\hline deal & 0 & 0 & 0 & 0 & 0 & 0 & 0 & 0 & 0 & 1 & 1 & 1 & 3 & 26 & 100 & 74 & 1050 \\
\hline addiction & 0 & 0 & 0 & 0 & 0 & 0 & 0 & 0 & 0 & 1 & 2 & 1 & 5 & 4 & 5 & 40 & 105 \\
\hline conscious & 0 & 0 & 0 & 0 & 0 & 0 & 0 & 0 & 0 & 1 & 0 & 0 & 1 & 6 & 48 & 598 & 1050 \\
\hline lifestyle & 0 & 0 & 0 & 0 & 0 & 0 & 0 & 0 & 0 & 0 & 6 & 0 & 9 & 19 & 63 & 361 & 105 \\
\hline crazy & 0 & 0 & 0 & 0 & 0 & 0 & 0 & 0 & 0 & 0 & 5 & 5 & 3 & 7 & 7 & 97 & 105 \\
\hline calorie & 0 & 0 & 0 & 0 & 0 & 0 & 0 & 0 & 0 & 0 & 0 & 1 & 0 & 0 & 1 & 15 & 18 \\
\hline guilt & 0 & 0 & 0 & 0 & 0 & 0 & 0 & 0 & 0 & 0 & 0 & 0 & 2 & 2 & 3 & 44 & 105 \\
\hline detox & 0 & 0 & 0 & 0 & 0 & 0 & 0 & 0 & 0 & 0 & 0 & 0 & 0 & 1 & 3 & 27 & 105 \\
\hline critics & 0 & 0 & 0 & 0 & 0 & 0 & 0 & 0 & 0 & 0 & 0 & 0 & 0 & 1 & 2 & 7 & 16 \\
\hline dictatorship & 0 & 0 & 0 & 0 & 0 & 0 & 0 & 0 & 0 & 0 & 0 & 0 & 0 & 0 & 5 & 18 & 18 \\
\hline indulgence & 0 & 0 & 0 & 0 & 0 & 0 & 0 & 0 & 0 & 0 & 0 & 0 & 0 & 0 & 0 & 11 & 30 \\
\hline Bigfoot & 0 & 0 & 0 & 0 & 0 & 0 & 0 & 0 & 0 & 0 & 0 & 0 & 0 & 0 & 0 & 28 & 105 \\
\hline crusade & 0 & 0 & 0 & 0 & 0 & 0 & 0 & 0 & 0 & 0 & 0 & 0 & 0 & 0 & 0 & 33 & 93 \\
\hline morality & 0 & 0 & 0 & 0 & 0 & 0 & 0 & 0 & 0 & 0 & 0 & 0 & 0 & 0 & 0 & 8 & 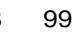 \\
\hline
\end{tabular}

Table 3: Websites using most compound types, December, 2008.

\begin{tabular}{|c|}
\hline \multicolumn{1}{|c|}{ Finance compounds } \\
\hline $\begin{array}{l}\text { www.unfccc.com; www.publicationsparliament.uk; www.iisd.ca; www.edf.org; } \\
\text { www.canada.com; www.pnl.gov; www.carbonneutral.com; www.accessaccounts.com; } \\
\text { www.climatescience.gov; www.globalcarbonproject.org; www.oecd.org; } \\
\text { www.iiasa.ac.at; www.aph.gov.au; www.climatechange.gov.au; www.iisd.ca; }\end{array}$ \\
\hline \multicolumn{1}{c|}{ Lifestyle compounds } \\
\hline $\begin{array}{l}\text { www.timesonline.co.uk; guardian.co.uk; www.carbontrust.co.uk; www.climateark.com; } \\
\text { www.climatespace.org; www.greendaily.com; www.plentymag.com; ww.archive.wn.com }\end{array}$ \\
\hline Attitudinal compounds \\
\hline $\begin{array}{l}\text { www.digg.com. www.blog.com.au, www.freerepublic.com, www.timesonline.co.uk; } \\
\text { www.greendaily.com; guardian.co.uk; www.peakenergy.blogspot.com; } \\
\text { http://archive.wn.com; www.climateark.com }\end{array}$ \\
\hline
\end{tabular}

